\title{
ISSUES OF IMPROVING QUALITY OF CONTACT WIRE
}

\author{
Isamukhamedov Dilshod Nigmatullaevich ${ }^{l}$, Madrahimov Daniyar Bakhtiyarovich ${ }^{l}$, Atamukhamedova Rano \\ Fazildzhanovna ${ }^{l}$, Tairova Nigora Jakhongirovna ${ }^{l}$ \\ ${ }^{1}$ Tashkent State Technical University named after Islam Karimov, 2 Universitety street, Tashkent, 100095, Uzbekistan
}

\begin{abstract}
The article deals with the issues of improving the reliability of cable operation and conductor products, due to its quality improvement. Research work was carried out on the example of a MF-100-grade contact wire, which is used in the operation of electrified railway and urban transport in the Republic of Uzbekistan and in other countries. The solution of the issue of improving reliability in the operation of the above-mentioned wire is reduced to improving the manufacturing technology, as well as making changes to the method of calculating the drawing route. The result of the work is the improvement of the performance parameters of the contact wire. Improving the quality of the contact lead is not the only advantage of this method; when replacing the number of wolves from 5 to 3 passes, it led to significant savings in the production process, and also made it possible to increase the reliability of the wire by an average of $1.2 \%$.

Keywords: rod, contact wire, shaped wire, drawing, technological process, drawing route, passage along drawing route, strength, operational characteristics, manufacturing technology, cable-conductor products.
\end{abstract}

The issues of improving reliability in the operation of cable lines are an urgent task for all manufacturers of cable and conductor products (CCP). The largest volume of consumption among the manufactured brands of cable-conductor products for electrified railway and urban transport in the Republic of Uzbekistan is the contact wire of the brand MF-100. At the same time, constant attention to the technology of production of cables and wires is to increase its strength and operational characteristics.

Contact wire was made of copper rolled wire with a diameter of $17 \mathrm{~mm}$ and had a strength of 36-37 $\mathrm{kg} \backslash \mathrm{mm}^{2}$ until 1970. It is known that with an increase in the degree of deformation, the metal is strengthened the stronger, the greater its deformation.

In 1961 an attempt was made to increase its strength by increasing the degree of deformation. A contact wire MF 100 was made from a $\varnothing-25 \mathrm{~mm}$ wire by drawing in 10 passes, which did not increase the strength, but on the contrary reduced it. At that time, this was not noticed and further experiments were abandoned. In 1970 contact wire is made from rolled wire of $\emptyset-18 \mathrm{~mm}$ produced by continuous casting and rolling. The strength of the contact wire increased to $37-39 \mathrm{~kg} \backslash \mathrm{mm}^{2}$. Further research and analysis of the results showed that in the future, increasing the strength of the contact wire is possible only from an alloyed copper rod. In 1999, a roll was made of copper doped with magnesium $\varnothing-16 \mathrm{~mm}$ by continuous casting and rolling on the line "SAUTWAER". The study and the obtained results showed increase in strength up to $40 \mathrm{~kg} \backslash \mathrm{mm}^{2}$, but this was significantly lower than the expected value of 42-43 $\mathrm{kg} \backslash \mathrm{mm}^{2}$ [1-4]. An analysis of drawing data revealed that drawing a contact wire from a rod of $\varnothing$ $16 \mathrm{~mm}$ in 5 passes increased the deformation fractionation and as a result, the final strength of the contact wire was reduced. In addition, during this period, the $\varnothing-8 \mathrm{~mm}$ rolled rod was made of a copper and phosphorus alloy, and when it was drawn into the $\varnothing-2.5 \mathrm{~mm}$ wire, it was not possible to obtain the expected strength of $60 \mathrm{~kg} \backslash \mathrm{mm} 2$. Analysis of the obtained drawing data revealed that reducing the degree of deformation from average values reduces the strength of the finished wire (see Table-1). 


\begin{tabular}{|c|c|c|c|c|c|}
\hline \multirow{2}{*}{ № } & Shape and & Section, & \multicolumn{2}{|c|}{ Drawing, $\boldsymbol{\mu}$} & \multirow{2}{*}{ Kg/mm $\mathbf{m}^{2}$} \\
\cline { 4 - 5 } size of rod, $_{\mathbf{m m}^{2} .}$ & private & common & \\
\hline $\mathbf{1}$ & $\mathbf{2}$ & $\mathbf{3}$ & $\mathbf{4}$ & $\mathbf{5}$ & $\mathbf{6}$ \\
\hline 0 & 8,20 & 67,2 & - & - & 31,4 \\
\hline 1 & 6,97 & 48,2 & 1,38 & 1,38 & 39,3 \\
\hline 2 & 5,99 & 35,9 & 1,35 & 1,87 & 43,5 \\
\hline 3 & 5,12 & 26,2 & 1,37 & 2,57 & 43,9 \\
\hline 4 & 4,34 & 18,8 & 1,39 & 3,58 & 45,9 \\
\hline 5 & 3,68 & 13,5 & 1,39 & 4,98 & 47,0 \\
\hline 6 & 3,24 & 10,5 & 1,29 & 6,40 & 48,5 \\
\hline 7 & 2,77 & 7,7 & 1,36 & 8,79 & 50,8 \\
\hline 8 & 2,50 & 6,25 & 1,23 & 10,76 & 49,5 \\
\hline 9 & 2,21 & 4,9 & 1,28 & 13,72 & 51,1 \\
\hline 1 & 1,98 & 3,92 & 1,25 & 17,15 & 44,2 \\
\hline 1 & 1,70 & 2,9 & 1,35 & 23,19 & 55,3 \\
\hline 1 & 1,50 & 2,25 & 1,29 & 29,88 & 56,8 \\
\hline
\end{tabular}

Alekhin V.YA. first paid attention to strength loss of contact wire made from located rolled rod due to small reduction in finishing wire. In his dissertation [5-6], results of performed analysis of contact wire drawing data from billet diameter of $25 \mathrm{~mm}$ and round copper-magnesium wire at its drawing from rolled rod of $\varnothing-8 \mathrm{~mm}$ to $\varnothing-1,5 \mathrm{~mm}$ showed [7-10] that the reduction in exhaust per pass is less than 1,25 generally results in reduced wire strength in this passage.

$1^{\text {st }}$ passes of drawing route

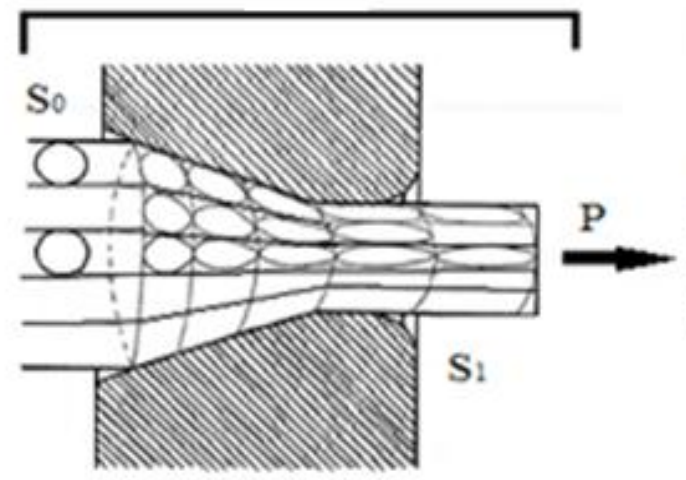

Scientific work in this direction is carried out within the framework of research at the departments "Electric Machines" and "Electromechanics and Electrotechnology" of Tashkent State Technical University by N.B. Pirmatov, V.P. Ivanova, V.V. Tsypkina [7]. In the field of issues studying the improvement of efficiency and drawing process reliability, the search for a technical solution was included, which made it possible to improve the operational parameters of conductive core of cable products - reducing electrical resistance by reducing the fractionation of deformation by recalculating the drawing route.

The manufacturing process of the finished cable product has the ultimate goal, which should provide high operational characteristics of the CCP, including a low value of the electrical (ohmic) resistance of the conductive core (CC). At the same time, well-tuned drawing technology, as an initial technological operation, has the greatest influence on the process of forming the structure of the conductive core [11-16].

Studies in the field of improving the quality of conductive core by I.Sh. Berin and N.Z. Dniester [9] made it possible to reduce the wire's electrical resistance at cold plastic deformation for copper to $3 \%$, and for aluminum to $1.5 \%$, which is explained by the theory of drawing (Fig. 1) for conductive core, which depends on the value of wire fractionation and deformation of uncovered wire reinforcing along the aisles (passes)

passes of drawing route- $n$

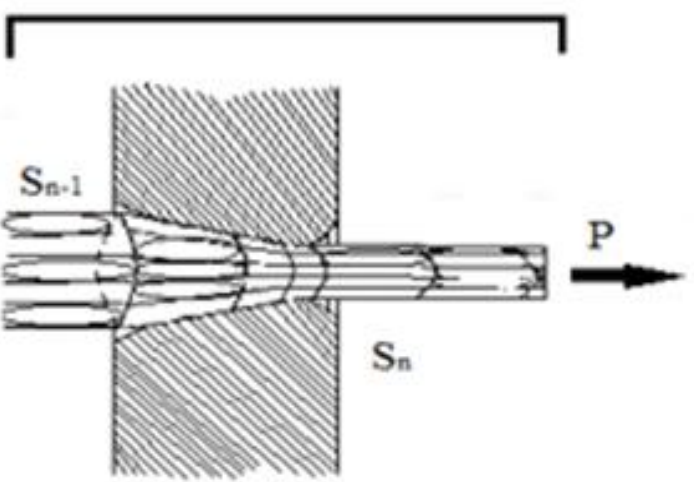

Fig. 1. Diagram of change of structural woven wire along drawing routes and influence of deformation fractionation on micro slip of copper wire samples [7]

In accordance with the above, the solution of the issue of reducing the electrical resistance of conductive core was achieved by reducing the deformation fractionation due to reducing the number of passes along the drawing route, i.e., reducing the number of drawing passes and working zones of plastic deformation (technological tool - dies) in which occurs structural changes of metal (Fig.1) [6].
Thus, the contact wire from a copper rod of $\varnothing-16$ $\mathrm{mm}$ in the framework of the scientific work [7] began to be drawn in 5 passes and this reduced the average draw due to an increase in the deformation fractionation. The result of this technology was reflected in a decrease in the strength of the contact wire.

Based on the data studied and after the calculations of the drawing route under the leadership 
of V.P. Ivanova and V.V. Tsypkina, the drawing technology of the MF-100 grade contact wire was changed to 3 passes, while the results of increasing the strength and cases of obtaining a contact wire with mechanical properties below GOST (state AllUnion standard) requirements were not achieved.

Improving the quality of the contact cause, this is not the only advantage of this method [7], when replacing the number of wolves from 5 to 3 passes, led to significant savings in the production process, which is expressed:

1) in reduction of metal consumption of drawing mill.

2) reducing the number of gearboxes (gears), which led to a clear decrease in losses in the gearbox system of the machine as a whole;

3) reduction of units of expensive drawing tool, namely die and, accordingly, losses on contact friction of tool surfaces with the object of treatment.

However, when putting this technology into production, the issue of redistributing payloads to machine elements that can negatively affect the work of the mill as a whole was also considered. This requires further research, but the findings suggest the following conclusions:

1. Increasing the number of wolves when drawing each wire size causes an increase in the fractional deformation of the structure of the material itself, therefore, switching to the production of a contact wire from 5 wolves to 3 reduces the fractional deformation, which leads to an increase in the strength of the contact wire while maintaining the required regulatory documentation electrical parameters;

2. In addition to the obvious advantages in the process and performance of this wire, one cannot fail to mention the significant economic effect, which in turn affects the savings in financial, raw materials and energy resources.

\section{References}

1. Alekhin Y.P., "Study of Technological Features of Production and Properties of a Rod and a Contact Wire Manufactured by the Method of Combined Casting and Rolling" dissertation work for the degree of Candidate of Technical Sciences

2. Razumov I.M., Perlin I.L. Technical rationing in the non-ferrous metalworking industry. Metallurgical Center, 1951.

3. Perlin I.L. Non-ferrous metals, 1959, No. 3, p.66

4. A.Krasilnikov, A.G. Lysenko Volochilshchik wire. Metallurgy, 1987.

5. A.K. Bulkhin, V.F. Kidyaev, S.A.Kizhaev Electric drive and automation of drawing equipment, part 1, Samara, 2002

6. Tsypkina V.V. Ivanova V.P. "Modeling of a resource-saving method of drawing," E3S Web of
Conference 139 (2019) $10 \quad 1073$ RSES 2019 (https://doi.org/10.1051/e3sconf/20191390 E 3S 139 (2019) 10 1073), 2019.

7. Ivanova V.P. "Increasing Energy and Resource Savings of Direct-Flow Drawing Mills," dissertation work for the degree of scientific degree (PhD) Ph.D. in Technical Sciences, Tashkent, 2019.

8. Tsypkina V.V., Ivanov A.A. Development of generalized requirements for the modernization of the electric drive of cable drawing machines//Universum: technical sciences: electron. scientific. zhurn. 2017. №4 (37).URL: https://7universum.com/ru/tech/ archive/item/4629 (case date: 24.10.2020).

9. Berin I.Sh., Dniester N.Z. Production of copper and aluminum wire, Metallurgy Publishing House. Moscow, 1974 S. 16-17.

10. Ivanova V.P., Yakubov B.E. Development of an information model of a resource-saving method of drawing//Universum: technical sciences: electron. scientific. zhurn. 2017. № 3 (36). URL: https://7universum.com/ru/tech/archive/item/4550 (case date: 24.10.2020).

11.Allayev, K.R., Fedorenko, G.M.,Postnikov, V.I.,Ostapchuk, L.B. Asynchronous generators as power system's natural dampers. 43rd International Conference on Large High Voltage Electric Systems 2010, CIGRE 20102010, 9p43rd International Conference on Large High Voltage Electric Systems 2010, CIGRE 2010; Paris; France; 22 August 2010.

12.Fazylov, Kh.F.,Allaev, K.R. Analysis of the operation of an electrical system during simultaneous operation of synchronous and asynchronous generators. Power engineering New York Volume 18, Issue 3, 1980, Pages 81-88.

13.Fazylov, Kh.F.,Allaev, K.R. Asynchronous turbogenerators with stator excitation and the prospects for their utilization. Power engineering New York Volume 23, Issue 2, 1985, Pages 7-13.

14.Fazylov, Kh.F.,Allaev, K.R. Calculation and experimental analysis of conditions of electrical power systems containing induction generators Power Engineering New York Volume 27, Issue 6, 1989, Pages 27-34.

15.Allaev K., Makhmudov T. Research of small oscillations of electrical power systems using the technology of embedding systems. Electrical Engineering, 2020; Issue 1: 309-319.DOI 10.1007/s00202-019-00876-9

16.Allaev K., Makhmudov T. Prospects of diversification and ensuring energy safety of Uzbekistan. E3S Web Conf., Volume 139, 2019, Rudenko International Conference "Methodological problems in reliability study of large energy systems" (RSES2019).https://doi.org/10.1051/e3sconf/201913 901002 